\title{
Bloodstream Infections due to Enterobacteriaceae Among Neonates in Poland - Molecular Analysis of the Isolates
}

\author{
AGNIESZKA CHMIELARCZYK, MONIKA POBIEGA*, JADWIGA WÓJKOWSKA-MACH, \\ DOROTA ROMANISZYN, PIOTR B. HECZKO and MAŁGORZATA BULANDA
}

Chair of Microbiology, Kraków, Poland

Submitted 21 January 2014, revised 27 February 2015, accepted 17 March 2015

\begin{abstract}
Bloodstream infections (BSIs) are associated with a significantly increased risk of fatality. No report has been found about the molecular epidemiology of Enterobacteriaceae causing BSI in neonates in Poland. The aim of this work was to determine the antibiotic resistance profiles, virulence gene prevalence, the epidemiological and genetic relationships among the isolates from Enterobacteriaceae causing BSI in neonates with birth weight $<1501 \mathrm{~g}$. Antimicrobial susceptibility testing was performed. PCR was performed to identify the presence of common beta-lactamase genes, virulence genes. PFGE and MLST were performed. The surveillance group contained 1,695 newborns. The incidence rate for BSIs was $5.9 \%$, the fatality rate $15 \%$. The most common species were Escherichia coli $(\mathrm{n}=24)$ and Klebsiella pneumoniae $(\mathrm{n}=16)$. CTX-M-15 was found in 6 E. coli, 8 K. pneumoniae, 1 Enterobacter cloacae strains. Among E. coli fim H (83.3\%), ibe A (37.5\%), neuC (20.8\%) were the most frequent. PFGE demonstrated unique pulsotypes among E. coli. E. coli ST131 clone was found in 7 E. coli strains. PFGE of 16 K. pneumoniae strains showed 8 pulsotypes. Five isolates from one NICU belonged to one clone. MLST typing revealed 7 different ST with ST336 as the most prevalent. This study provides information about resistance, virulence and typing of Enterobacteriaceae strains causing BSI among neonates. E. coli and Klebsiella spp. isolated in this study have completely different epidemiology from each other.
\end{abstract}

Key words: Enterobacteriaceae, Escherichia coli ST131, Klebsiella pneumoniae, bloodstream infections, MLST, very-low birth weight neonates

\section{Introduction}

Bloodstream infections (BSIs) are the most common nosocomial infections among neonates, associated with a significantly increased risk of fatality (Stoll et al., 2002). Newborns, especially those with very low birth weight (VLBW) are primarily at risk of developing late-onset BSIs (LO-BSIs), caused by organisms acquired perinatally or postnatally, usually as a consequence of nosocomial transmission. The main risk factors for LO-BSI include prematurity, prolonged stay in a neonatal intensive care unit (NICU) and administration of invasive procedures (Ozkan et al., 2014). Consequently, the improved survival rates of small premature infants experiencing long stays in modern NICUs, which are better equipped for life-saving intensive care, has been a major factor in the increase in LO-BSI caused by Gram-negative bacteria (Cordero et al., 2004; Wojkowska-Mach et al., 2013). Enterobacteriaceae are second only to coagulase-negative staphylococci (CoNS) in causing LO-BSIs (Karlowicz et al., 2000; Lutsar et al., 2014). Prolonged use of broad-spectrum antibiotics in NICUs is associated with the occur- rence of multi-drug resistant (MDR) bacteria. Selection of more broadly resistant Gram-negative enteric bacteria is linked with outbreaks of bacterial disease in NICUs (Cordero et al., 2004).

Nosocomial isolates such as Escherichia coli and Klebsiella sp. often have extended spectrum $\beta$-lactamase (ESBL) phenotypes, and E. coli strains carrying these enzymes have disseminated into the community. One of the best examples of this trend is the global spread of the clonal E. coli sequence type (ST) 131 (ST131), which expresses CTX-M enzymes. (Birgy et al., 2013) In contrast, among Klebsiella strains, relatively few of the serotypes (particularly K1 and K2) appear to be linked with invasive strains. Also, the hypermucoviscous phenotype, strongly associated with the presence of rpmA and magA genes, is a virulence marker in clinical strains (Jung et al., 2013). In Klebsiella pneumoniae, CTX-M-15 is mainly associated with quinoloneresistant strains, belonging to ST11 clone (Damjanova et al., 2008; Oteo et al., 2009).

Despite many reports of ESBL-producing isolates among Polish hospitals, no report has been found about the molecular epidemiology of Enterobacteriaceae

\footnotetext{
* Corresponding author: M. Pobiega, Chair of Microbiology, Krakow, Poland; e-mail: monika.pobiega@gmail.com
} 
causing BSI in neonates. Here, we collected clinical isolates from Enterobacteriaceae family bacteria originating from BSIs of neonates hospitalized in six Polish NICUs to determine their antibiotic resistance profiles, virulence gene prevalence, and the epidemiological and genetic relationships among the isolates. Here we have focused on detailed molecular studies, data about epidemiology of bloodstream infections in newborns are included in other manuscripts (WojkowskaMach et al., 2014).

\section{Experimental}

\section{Materials and Methods}

Study population. Prior to the study, a confirmatory ethics vote for the data collected in the Polish Neonatology Surveillance Network (PNSN) for the scientific purpose was approved by the Bioethics Committee of Jagiellonian University Medical College (No KBET/221/B/2011).

Continuous prospective target surveillance of infections was conducted from 1/1/2009 through 12/31/2011 at Polish NICUs (only teaching hospitals) which participated in PNSN. These tertiary NICUs provided care for $20 \%$ of all VLBW infants born in Poland annually. The surveillance included infants hospitalized in these NICUs whose birth weights were $<1500$ grams (VLBW) at birth until they achieved a weight of 1800 grams or died. The study covered 1,695 newborns. The general fatality case rate was $16.3 \%$. All VLBW infants of suspected or documented infected were subject to registration regardless of the time of occurrence according to criteria of Gastmeier et al. (2004) when they had clinical signs of a bloodstream infection (BSI) (Gastmeier et al., 2004).

- at least 2 of the following: temperature $>38^{\circ} \mathrm{C}$ or $<36.5^{\circ} \mathrm{C}$ or temperature instability, tachycardia or bradycardia, apnea, prolonged capillary refill, metabolic acidosis, hypoglycemia and other signs of bloodstream infections such as lethargy;

- and patients who had 1 of the following criteria: C-reactive protein $>2.0 \mathrm{mg} / \mathrm{dl}$, immature/ total neutrophil ratio (I/T ratio) $>0.2$, leukocytes $<5000 / \mu \mathrm{l}$ and platelets $<10000 / \mu \mathrm{l}$.

LO-BSI was defined when diagnosed $>72$ hours after delivery. Clinical sepsis represented an infant where signs of infection existed but on blood culture a causative organism was not identified.

Central venous catheter (CVC)-associated BSI (CVC-BSI) and peripheral intravenous catheter (PVC)associated BSI (PVC-BSI) were defined as infections associated with the use of a central or peripheral venous catheter within the preceding 48 hours prior to the onset of the infection (Gastmeier et al., 2004).
Bacterial strains. The present study examined 55 Enterobacteriaceae family isolates originating from BSIs: 4 from early onset infections (EOI), 51 from LOI. The majority originated from NICUs VI and II ( 25 and 12, respectively). The remainder were from V (8), I (5), III (3) and IV (2).

Culture and species identification. All blood specimens of at least $1 \mathrm{ml}$ were injected into an aerobic blood culture bottle (Bactec Plus 26 Aerobic; Becton Dickinson, Poland), and cultured on MacConkey agar, Columbia agar (at $37^{\circ} \mathrm{C}$, each for $24 \mathrm{~h}$ ) and Sabouraud agar (at $37^{\circ} \mathrm{C}, 48$ hours) (all from BIOCORP, Poland). Collection and identification of the bacterial strains was performed in the local microbiology laboratories of each hospital. Isolates were identified by the automated identification system (VITEK 2; bioMérieux, Warsaw, Poland). Bacterial strains were stored at $-70^{\circ} \mathrm{C}$ and sent to Department of Microbiology, Krakow.

Antimicrobial susceptibility tests. Isolates were tested using disk diffusion antimicrobial susceptibility methods on Mueller-Hinton agar plates according to the current European Committee on Antimicrobial Susceptibility Testing (EUCAST) guidelines using clinical breakpoint tables v. 3.1 (http://www. eucast. org v.3.1, accessed: 11.02.2013). All discs were obtained from Oxoid, Basingstoke. ESBL activity was detected using a modified double-disk synergy test (Drieux et al., 2008). ESBL-positive strains resistant to at least two other groups of antibiotics were considered to be MDR.

DNA isolation. DNA templates were extracted using a Genomic Mini kit (A\&A Biotechnology, Poland) according to manufacturer's instructions.

Polymerase chain reaction (PCR) for extendedspectrum $\beta$-lactamase genes and virulence factor screening. PCR was performed to identify the presence of $b l a_{\text {СТХ-М }}, b l a_{\mathrm{SHV}}$ and $b l a_{\text {TEM }}$ genes (Chmielarczyk et al., 2013; Monstein et al., 2007), products were sequenced by commercial company (Genomed, Warsaw, Poland).

E. coli was checked for the presence of selected virulence genes as described elsewhere (Chmielarczyk et al., 2013; Johnson and Stell, 2000; Watt et al., 2003).

The isolates were classified to 1 of the 4 main $E$. coli phylogenetic groups (A, B1, B2, and D) (Chmielarczyk et al., 2013; Clermont et al., 2000).

K. pneumoniae was tested for the presence of $r m p \mathrm{~A}$ (regulator of mucoid phenotype A), magA (mucoviscosity-associated gene A), wabG (involved in the biosynthesis of the outer core lipopolysaccharide), uge (encoding uridine diphosphate galacturonate 4-epimerase, which is responsible for capsule biosynthesis), $k f u$ (iron uptake system), and alls (encoding the activator of the allantoin regulon) (Brisse et al., 2009). PCR was performed with primer pairs specific for the K. pneumoniae capsule gene cluster (cpsK1, cpsK2) 
(Fang et al., 2007; Turton et al., 2008). NCTC 5054 and NCTC 5055 were used as positive controls for $c p s \mathrm{~K} 1$ and $c p s \mathrm{~K} 2$, respectively.

Pulsed-field gel electrophoresis (PFGE). All isolates were analyzed using the standardized PFGE protocol developed at the Centers for Disease Control and Prevention by the PulseNet program. XbaI (Thermo Scientific) was used for DNA digestion. The digested products were separated on a CHEF III PFGE system (BioRad, Warsaw, Poland) in $0.5 \times$ Tris-borate-EDTA buffer at $14^{\circ} \mathrm{C}$ at $6 \mathrm{~V}$ for $20 \mathrm{~h}$ with a ramped pulse time of $2.2-54.2 \mathrm{~s}$ for E. coli and $14^{\circ} \mathrm{C}$ at $6 \mathrm{~V}$ for $22 \mathrm{~h}$ with a ramped pulse time of 2-35 s for K. pneumoniae, Klebsiella oxytoca, Enterobacter cloacae and Serratia marcescens. GelCompar (Applied Maths, Kortrijk, Belgium) was used for cluster analysis with the unweighted pair group method with an arithmetic mean and the Dice coefficient similarity require to be $>90 \%$ for the pattern to be considered as belonging to the same type.

Multilocus sequence typing (MLST). MLST for E. coli was performed in accordance with (Wirth et al., 2006) (http://mlst.ucc.ie/mlst/dbs/Ecoli), for K. pneumoniae was performed in accordance with (Diancourt et al., 2005) (http://www.pasteur.fr/recherche/genopole/ $\mathrm{PF} 8 / \mathrm{mlst} /$ Kpneumoniae.html).

\section{Results}

The surveillance group contained 1,695 newborns with birth weight below $1500 \mathrm{~g}$. Data on gestational age, mode of delivery, birth weight, multiple birth were previously published (Wojkowska-Mach et al., 2014). In the study group, 100 cases of Enterobacteriaceae BSI were registered. Among all the etiological factors for BSI, bacteria belonging to Enterobacteriaceae family were responsible for $15.2 \%$ of such infections. The incidence rate for Enterobacteriaceae BSIs was 5.9\%, while the fatality rate was $15 \%$. The fatality rate for $E$. coli was $26.0 \%$ and for Klebsiella sp. $10.0 \%(\mathrm{p}=0.09)$. Of the 55 Enterobacteriaceae isolates included in our study, there were 24 E. coli, 16 K.pneumoniae, 4 K. oxytoca, 5 E. cloacae, 1 Enterobacter sakazakii, 4 S. marcescens and 1 Morganella morganii (Table I).

The CVC utilization rate was 0.45 and the PVC utilization rate was 0.16 (calculated by dividing the number of days of CVC/PVC by the total number of patient days). Among the infections caused by E. coli, 20.8\% of LO-BSIs were associated with CVC use, while $8.3 \%$ were associated with PVC use. Among the LO infections caused by K. pneumoniae, $43.75 \%$ were associated with CVC and $18.75 \%$ with PVC.

Table I

Participation of particular isolates in species and NICU.

\begin{tabular}{|c|c|c|c|c|c|c|c|c|c|c|}
\hline \multirow{2}{*}{ NICU } & \multicolumn{3}{|c|}{ Escherichia coli $(\mathrm{n}=24)$} & \multicolumn{3}{|c|}{ Klebsiella pneumoniae $(\mathrm{n}=16)$} & \multirow{2}{*}{$\begin{array}{c}\text { Entero- } \\
\text { bacter sp. } \\
\quad(\mathrm{n}=6)\end{array}$} & \multirow{2}{*}{$\begin{array}{c}\text { Klebsiella } \\
\text { oxytoca } \\
(\mathrm{n}=4)\end{array}$} & \multirow{2}{*}{$\begin{array}{c}\text { Serratia } \\
\text { marcescens } \\
(\mathrm{n}=4)\end{array}$} & \multirow{2}{*}{$\begin{array}{c}\text { Morganella } \\
\text { morganii } \\
(\mathrm{n}=1)\end{array}$} \\
\hline & & $S T$ & Pulsotype & & $S T$ & Pulsotype & & & & \\
\hline \multirow[t]{2}{*}{$I(n=5)$} & 1 & ST141 & unique & 1 & ST153 & unique & 2 & & & \\
\hline & 1 & ST73 & unique & & & & & & & \\
\hline \multirow[t]{4}{*}{ II $(n=12)$} & 4 & ST131 & unique & & & & 1 & 3 & & \\
\hline & 2 & ST69 & $\begin{array}{l}\text { identical } \\
\text { (the same patient) }\end{array}$ & & & & & & & \\
\hline & 1 & ST69 & unique & & & & & & & \\
\hline & 1 & ST75 & unique & & & & & & & \\
\hline III $(\mathbf{n}=3)$ & & & & 1 & ST336 & unique & & & 1 & 1 \\
\hline IV $(n=2)$ & & & & & & & & & 2 & \\
\hline \multirow[t]{4}{*}{$V(\mathbf{n}=8)$} & 2 & ST131 & unique & 2 & ST17 & $\begin{array}{l}\text { identical } \\
\text { (the same patient) }\end{array}$ & & 1 & & \\
\hline & 1 & ST141 & unique & & & & & & & \\
\hline & 1 & ST69 & unique & & & & & & & \\
\hline & 1 & ST543 & unique & & & & & & & \\
\hline \multirow[t]{7}{*}{$\mathrm{VI}(\mathrm{n}=25)$} & 3 & ST998 & unique & 5 & ST336 & clone A & 3 & & 1 & \\
\hline & 1 & ST131 & unique & 2 & ST11 & clone B & & & & \\
\hline & 1 & ST141 & unique & 2 & ST6 & clone $\mathrm{C}$ & & & & \\
\hline & 1 & ST69 & unique & 1 & ST6 & unique & & & & \\
\hline & 1 & ST95 & unique & 1 & ST153 & unique & & & & \\
\hline & 1 & ST569 & unique & 1 & ST870 & unique & & & & \\
\hline & 1 & $\begin{array}{l}\text { non } \\
\text { typeable }\end{array}$ & unique & & & & & & & \\
\hline
\end{tabular}


Table II

Non-susceptible strains among different species of Enterobacteriaceae family.

\begin{tabular}{|c|c|c|c|c|c|c|}
\hline & $\begin{array}{c}\text { Escherichia coli } \\
\mathrm{n}=24(\%)\end{array}$ & $\begin{array}{c}\text { Klebsiella } \\
\text { pneumoniae } \\
\mathrm{n}=16(\%)\end{array}$ & $\begin{array}{c}\text { Enterobacter sp. } \\
\mathrm{n}=6(\%)\end{array}$ & $\begin{array}{c}\text { Klebsiella } \\
\text { oxytoca } \\
\mathrm{n}=4(\%)\end{array}$ & $\begin{array}{c}\text { Serratia } \\
\text { marcescens } \\
\mathrm{n}=4(\%)\end{array}$ & $\begin{array}{c}\text { Morganella } \\
\text { morganii } \\
\mathrm{n}=1(\%)\end{array}$ \\
\hline \multicolumn{7}{|l|}{ Penicillins } \\
\hline Ampicillin & $22(91.7)$ & $16(100)$ & nd & $4(100)$ & nd & nd \\
\hline Amoxicillin-clavulanate & $13(54.2)$ & $9(56.3)$ & nd & $2(50)$ & nd & nd \\
\hline Piperacillin-tazobactam & $0(0)$ & $2(12.5)$ & $1(16.7)$ & $0(0)$ & $0(0)$ & $0(0)$ \\
\hline \multicolumn{7}{|l|}{ Cephalosporins } \\
\hline Cefepime & $6(25)$ & $9(56.3)$ & $0(0)$ & $0(0)$ & $0(0)$ & $0(0)$ \\
\hline Cefotaxime & $5(20.8)$ & $9(56.3)$ & $2(33.3)$ & $0(0)$ & $1(25)$ & $1(100)$ \\
\hline Ceftazidime & $6(25)$ & $9(56.3)$ & $1(16.7)$ & $0(0)$ & $1(25)$ & $0(0)$ \\
\hline Cefuroxime & $6(25)$ & $9(56.3)$ & nd & $0(0)$ & nd & nd \\
\hline \multicolumn{7}{|l|}{ Carbapenems } \\
\hline Doripenem & $1(4.2)$ & $3(18.8)$ & $0(0)$ & $0(0)$ & $0(0)$ & $0(0)$ \\
\hline Ertapenem & $2(8.3)$ & $3(18.8)$ & $2(33.3)$ & $0(0)$ & $0(0)$ & $1(100)$ \\
\hline Imipenem & $1(4.2)$ & $0(0)$ & $0(0)$ & $0(0)$ & $0(0)$ & $0(0)$ \\
\hline Meropenem & $1(4.2)$ & $0(0)$ & $0(0)$ & $0(0)$ & $0(0)$ & $0(0)$ \\
\hline \multicolumn{7}{|l|}{ Monobactams } \\
\hline Aztreonam & $8(33.3)$ & $13(81.3)$ & $2(33.3)$ & $1(25)$ & $1(25)$ & $1(100)$ \\
\hline \multicolumn{7}{|l|}{ Fluoroquinolones } \\
\hline Ciprofloxacin & $5(20.8)$ & $7(43.8)$ & $0(0)$ & $0(0)$ & $0(0)$ & $0(0)$ \\
\hline \multicolumn{7}{|l|}{ Aminoglycosides } \\
\hline Amikacin & $2(8.3)$ & $2(12.5)$ & $0(0)$ & $0(0)$ & $0(0)$ & $0(0)$ \\
\hline Gentamicin & $3(12.5)$ & $3(18.8)$ & $0(0)$ & $0(0)$ & $0(0)$ & $0(0)$ \\
\hline Tobramycin & $6(25)$ & $8(50)$ & $0(0)$ & $0(0)$ & $0(0)$ & $1(100)$ \\
\hline \multicolumn{7}{|l|}{ Tetracyclines } \\
\hline Tigecycline & $0(0)$ & $0(0)$ & $0(0)$ & $0(0)$ & $0(0)$ & $0(0)$ \\
\hline \multicolumn{7}{|l|}{ Miscellaneous } \\
\hline Chloramphenicol & $1(4.2)$ & $3(18.8)$ & $0(0)$ & $0(0)$ & $0(0)$ & $0(0)$ \\
\hline Trimethoprim-sulfamethoxazole & $10(41.7)$ & $6(37.5)$ & $0(0)$ & $0(0)$ & $0(0)$ & $0(0)$ \\
\hline
\end{tabular}

The highest level of resistance among E. coli isolates was observed against AMP (91.7\%), AMC (54.2\%), SXT (41.7\%) and ATM (33.3\%). The highest level of resistance among $K$. pneumoniae isolates was observed against AMP (100\%), ATM (81.3\%), AMC (56.3\%), all the cephalosporins investigated herein $(56.3 \%)$, and CIP (43.8\%) (Table II). The ESBL phenotype was found among 16 isolates (29\%), with nine K. pneumoniae, six E. coli and one E. cloacae.

Molecular characterization showed that all ESBLpositive isolates carried the $b l a_{\text {СTX-M }}$ gene: 15 of them had CTX-M-15 and one had CTX-M-3. Eleven isolates $(68.8 \%)$ harbored the TEM-1 gene together with the CTX-M gene. Five isolates harbored the SHV-11 gene and one harbored SHV-1 together with CTX-M. Four isolates harbored CTX-M-15 gene together with TEM-1 gene and SHV-11 gene. One isolates harbored CTX-M-15 gene together with TEM-1 gene and SHV-1 gene. Ten of the ESBL-positive strains (5 E.coli and $5 \mathrm{~K}$. pneumoniae) were regarded as MDR types.
The most frequently detected genes among the E. coli isolates were iron-related genes including fhuA (91.7\%), fecA (75\%), iutA (58.3\%), fyuA (54.2\%), iro N (50\%) and iucC (50\%), iha (8.3\%). The most frequently detected adhesion gene was fim $\mathrm{H}$ (found in $83.3 \%$ of the isolates). The ibeA gene was found in $37.5 \%$ of isolates, while the neuC gene was found in $20.8 \%$ of isolates.

Sixteen $(66.6 \%)$ isolates clustered in the ECOR group B2, 6 (25.0\%) in D, 1 (4.2\%) in A, and $1(4.2 \%)$ in group B1.

None of the K. pneumoniae strains tested here were the capsular K1 or K2 type. Additionally, the magA gene was not identified in the isolates. In contrast, the gene uge was detected in all of the K. pneumoniae strains, while wabG was present in 11 of them (68.8\%). Only one isolate harbored alls (no 75), while another harbored $k f u$ and $r p m$ genes (no 220).

PFGE typing demonstrated that almost all of the 24 E. coli isolates had unique pulsotypes. Two strains with identical pulsotypes were isolated from the same patient. 
PFGE-Xbal

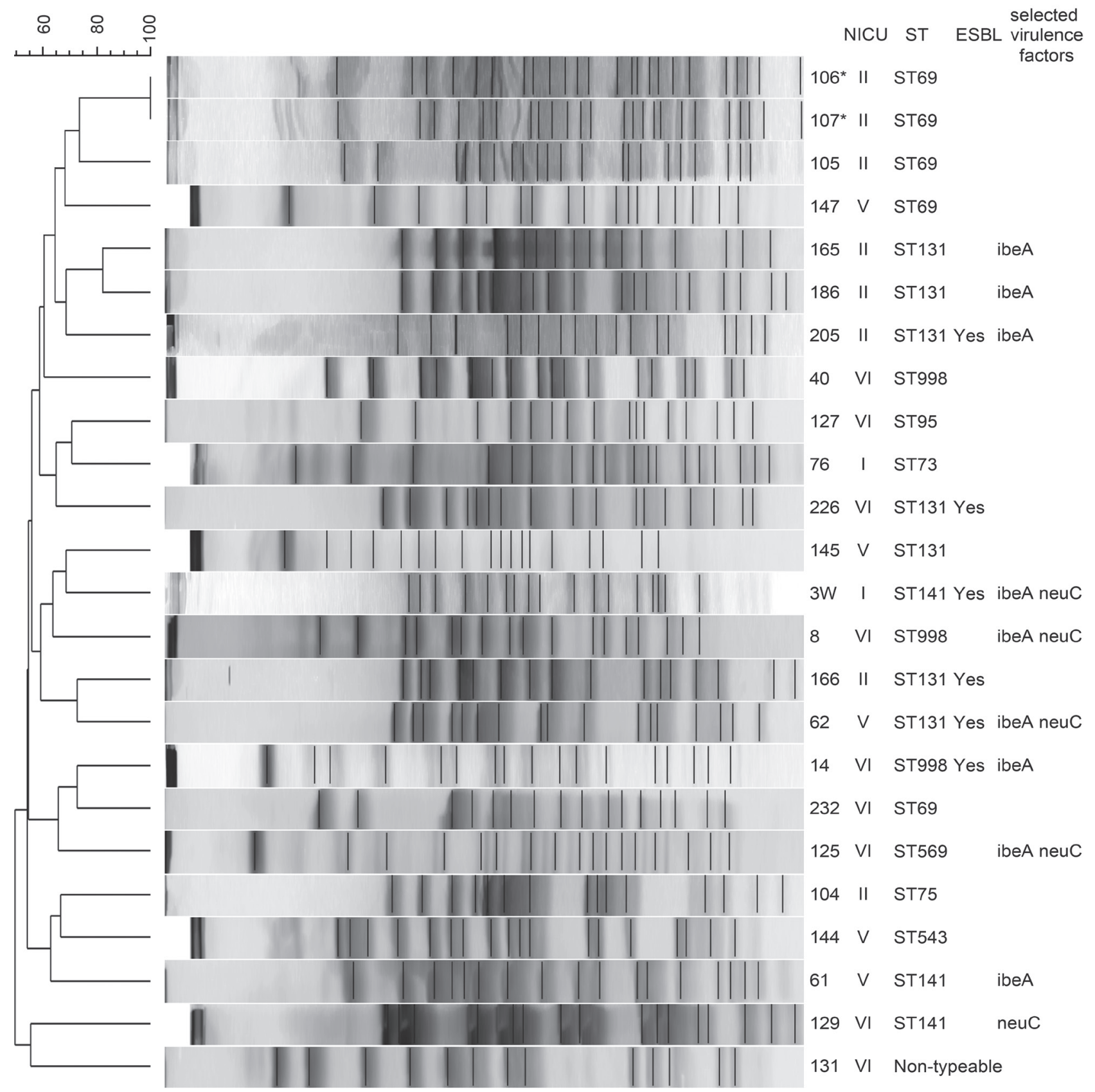

Fig. 1. Dendrogram of E. coli isolates. NICU was designated by Roman numerals. Asterisks indicate isolates derived from the same patient.

MLST typing revealed 10 different sequence types; these included ST131 (7 isolates), ST69 (5), ST141 (3), ST998 (3), ST73 (1), ST75 (1), ST95 (1), ST543 (1) and ST569 (1). One isolate could not be typed. Four among the ST131 isolates were from NICU II (Fig. 1). PFGE typing of $16 \mathrm{~K}$.pneumoniae strains showed eight different pulsotypes. Five isolates from NICU VI belonged to one clone A. Those isolates were detected in 2009, 2010 and 2011. The mortality connected with those strains was $21.4 \%$. Clone B consisted of two isolates similarly to clone $\mathrm{C}$ while the remaining five isolates had unique pulsotypes. MLST typing revealed seven different sequence types: ST 336 (6 isolates), ST6 (3), ST 11 (2) ST17 (2),
ST153 (1), ST321 (1), and ST 870 (1). The main clone identified by PFGE was compatible with ST 336 (Fig. 2). PFGE typing of the E. cloacae strains revealed unique pulsotypes. Among K. oxytoca, two strains with identical pulsotypes were from the same patient, as was in the case for S. marcescens (data not shown).

\section{Discussion}

Enterobacteriaceae remain one of the most important, albeit not the most frequent, cause of BSIs. Septicaemia or BSI in neonates is an important cause of neonatal mortality and morbidity in developing 


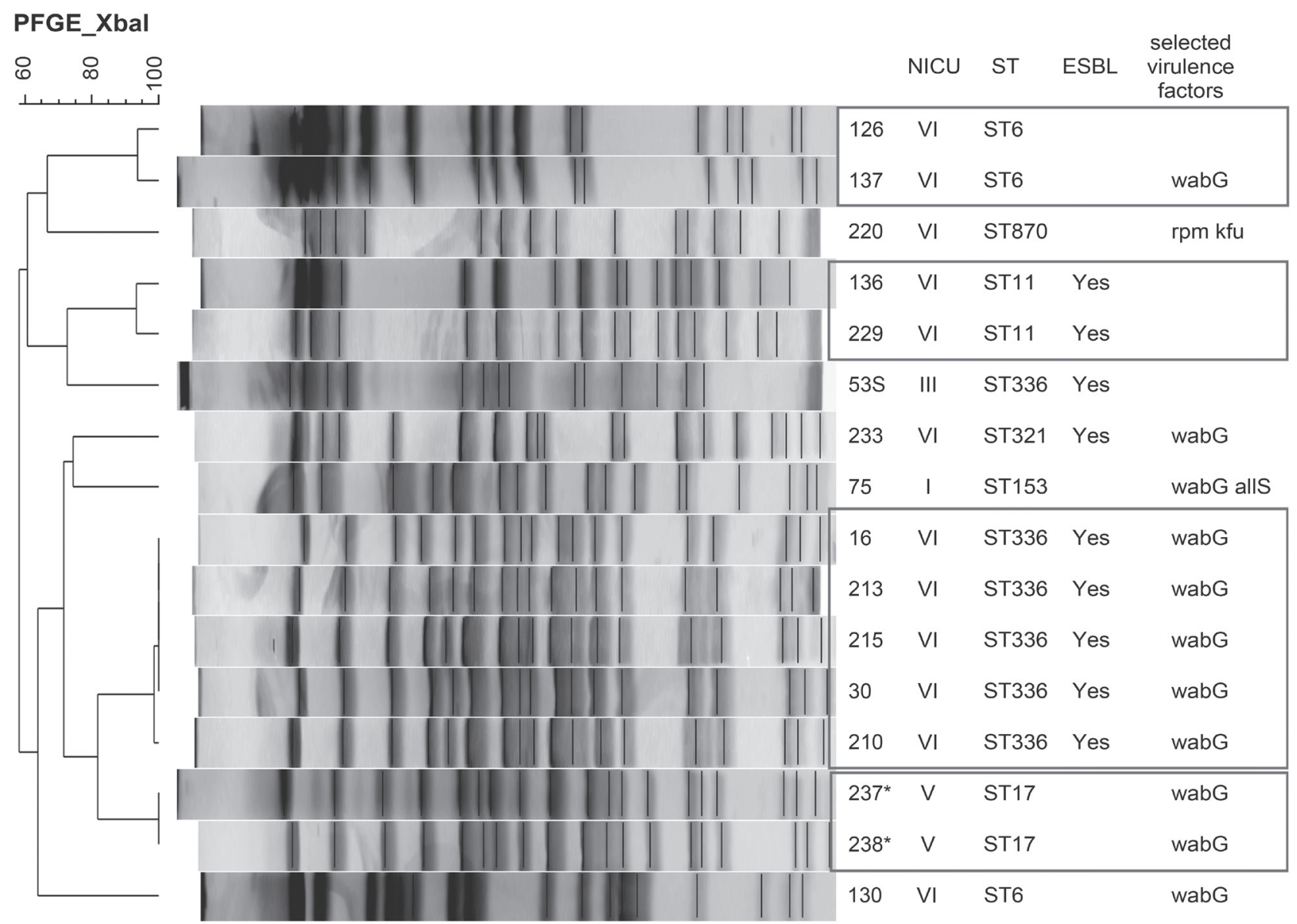

Fig. 2. Dendrogram of K. pneumoniae isolates. NICU was designated by Roman numerals. Detected clones were marked by frames. Asterisks indicate isolates derived from the same patient.

countries and K. pneumoniae and E. coli are prominent causative agents. In a study of 6215 infants admitted to the National Institute of Child Health and Human Development (NICHD) Neonatal Research Network (NRN) centers, $70 \%$ of first episode late-onset infections were caused by Gram-positive organisms, with coagulase-negative staphylococci accounting for $48 \%$ of the infections; however, the death rates were highest for infants infected with E. coli. (Karlowicz et al., 2000) Studies conducted by Makhoul et al. (2005) showed that mortality rate was about 4 times higher for infections caused by E. coli and 6 times higher for K. pneumoniae than for CoNS infections. Gram-negative bacilli (GNB) have been shown to be the non-dominant group of etiological risk factors for BSI, representing 20-30\% of the infections in some studies (Graham et al., 2006; Mitt et al., 2014; Nagao, 2013). A study conducted by Cordero et al. (2004) showed that $20 \%$ of BSI episodes were caused by GNB, of which 15\% were Enterobacteriaceae. Identification of these microorganisms in our study group was $15.2 \%$ and, importantly, infection with these etiological agents has been shown to be connected with high mortality rates in neonates (15\%). Stoll et al. (2011) has described E. coli as the major causative patho- gen of BSIs in preterm infants and the second most common cause of BSIs in term infants. Vergnano et al. (2011) indicated that E. coli was the third most common microorganism isolated from neonates and reported a prevalence of $13 \%$ in the UK, whereas in Germany the prevalence was $4.8 \%$ (Geffers et al., 2008), which is about three times less than that observed in NICUs in the present study. Unfortunately, E. coli is frequently associated with severe infections and is the leading cause of sepsis-related mortality among VLBW infants. Indeed, E. coli accounted for $24.5 \%$ of EOI of neonates in the United States (Weston et al., 2011) and 14.6\% in Polish VLBW infants (Chmielarczyk etal., 2014). In the present study, other Enterobacteriaceae family microorganisms such as Klebsiella spp. and Enterobacter spp. were markedly less common, similar to other studies (Cordero et al., 2004; Geffers et al., 2008; Lombardi et al., 2014; Nagao, 2013; Vergnano et al., 2011).

Crossing the skin barrier provides a direct route of invasion for bacteria; therefore, insertion of a CVC and the length of its duration in situ are risk factors for the development of a BSI. Lombardi et al. (2014) showed that in the neonatal pathology ward CVC infections reached $36.3 \%$ among Gram-negative bacteria, and 
Klebsiella spp. were the most frequently isolated. This result is similar to our data.

E. coli and Klebsiella spp. isolated from NICUs in this study have different epidemiology to each other; hence, they require different surveillance and infection control. According to PFGE results, E. coli comprised different clones, while among the K. pneumoniae isolates, some showed high genetic similarity. Similar findings have been reported previously by other authors. (Castro et al., 2010; Wojkowska-Mach et al., 2013) Of the six NICUs we investigated, the majority of the Enterobacteriaceae isolates were from NICU VI, where Klebsiella dominated; this finding may be related to clonal spread of these bacteria. The Klebsiella clones detected in our study belong to four sequence types (ST): ST6, ST11, ST17 and ST336, of which ST11 and ST17 are known pathogens and colonizers widely distributed in Europe (Damjanova et al., 2008; Oteo et al., 2009).

The MLST technique showed that seven E.coli strains belonged to ST131, but according to the PFGE results, these strains had unique pulsotypes and came from three different centers; hence, they are assumed not to be clonally spread. It has been reported that strains belonging to the same ST do not always cluster in a single branch based on cluster analysis of PFGE patterns (Vimont et al., 2008). ST131 is often reported in adults and recently also in children and neonates, and is probably transmitted between mothers and neonates (Denkel et al., 2014). The spread of ESBL-producing ST131 E. coli in the community, especially during the neonatal period, is a cause for serious concern (Birgy et al., 2013). Recently, a CTX-M-15 ESBL-positive E. coli ST131 clone, belonging to the B2 phylogenetic group and characterised by a particular antimicrobial resistance and high virulence potential, became a major public health problem especially in developing countries (Brisse et al., 2012; Clermont et al., 2009).

The microorganisms responsible for neonatal BSI have changed over time and vary from place to place. Prolonged use of broad-spectrum antibiotics in NICUs is associated with the current epidemic of MDR Gramnegative bacteria. Biedenbach et al. (2004) reported that the neonatal sepsis rate from Klebsiella spp. was higher in Latin America than in North America and was correlated with the use of extended-spectrum antibiotics. Klebsiella spp. and E. coli had the highest level of resistance to ampicillin, amoxicillin and aztreonam, which may have been caused by frequent administration of these drugs. Studies about antibiotic consumption conducted on the Polish NICUs have shown that beta-lactams were administred in more than $50 \%$ of infections (Rozanska et al., 2012). In our study, higher levels of antibiotic resistance (and more ESBL-positive strains) were observed among Klebsiella strains, probably as a result of the epidemic clone detected in NICU VI.
The E. coli isolates studied here were more likely to posses the ibeA gene than those derived from urinary and respiratory tract infections (Chmielarczyk et al., 2013). Soto et al. found that strains causing EOI harbored a higher frequency of the ibeA gene (Soto et al., 2008). Among Klebsiella sp. only some of the isolates possessed virulence genes such as rpmA or $k f u$. None of the isolates possessed $\mathrm{K} 1$ or $\mathrm{K} 2$ serotypes. As the capsule is a major virulence factor for K. pneumoniae (Cortes et al., 2002), information about the prevalence of the capsular types in such infections is an essential component of infection prevention and control (Pan et al., 2013).

According to the results, contact isolation is required when a patient is colonized or infected by a microorganism which is transmitted by direct physical contact. The presented results have shown that reliable adherence to that principle by the personnel is necessary when Klebsiella spp. is highly level of endemic or in case of epidemic. However, data about E. coli showed that precautions should be different and regimen about hand hygiene is insufficient. In the case of E. coli surveillance on people who take care of a neonate including mother and people performing Kangaroo care, could be performed. Infection prevention should also require intensive education and preparing procedures about Kangaroo care, feeding and milk expression (including milk storage) (Guzman-Cottrill et al., 2013).

\section{Acknowledgements}

The authors wish to thank the staff in NICUs for their help and interest in the study.

\section{Funding}

This work was supported by a grant from the Ministry of Science and Higher Education (DEC-2011/01/D/N27/00104). The sponsors provided the funding for the project only.

\section{Literature}

Biedenbach D.J., G. J. Moet and R. N. Jones. 2004. Occurrence and antimicrobial resistance pattern comparisons among bloodstream infection isolates from the SENTRY Antimicrobial Surveillance Program (1997-2002). Diagn. Microbiol. Infect. Dis. 50: 59-69.

Birgy A., P. Mariani-Kurkdjian, P. Bidet, C. Doit, N. Genel, C. Courroux, G. Arlet and E. Bingen. 2013. Characterization of extended-spectrum-beta-lactamase-producing Escherichia coli strains involved in maternal-fetal colonization: prevalence of E. coli ST131. J. Clin. Microbiol. 51: 1727-1732.

Brisse S., C. Fevre, V. Passet, S. Issenhuth-Jeanjean, R. Tournebize, L. Diancourt and P. Grimont. 2009. Virulent clones of Klebsiella pneumoniae: identification and evolutionary scenario based on genomic and phenotypic characterization. PLoS One 4: e4982.

Brisse S., L. Diancourt, C. Laouenan, M. Vigan, V. Caro, G. Arlet, L. Drieux, V. Leflon-Guibout, F. Mentre, V. Jarlier and others. 2012. Phylogenetic distribution of CTX-M- and non-extendedspectrum-beta-lactamase-producing Escherichia coli isolates: group B2 isolates, except clone ST131, rarely produce CTX-M enzymes. J. Clin. Microbiol. 50: 2974-2981. 
Castro B., I. Montesinos, P. Fuster-Jorge, T. Delgado, M.A. MiguelGomez and A. Sierra. 2010. Epidemiology of Enterobacteriaceae causing bloodstream infections in neonatal intensive care unit patients. Enferm. Infecc. Microbiol. Clin. 28: 227-232.

Chmielarczyk A., M. Pobiega, J. Wojkowska-Mach, D. Romaniszyn, P. Adamski, P.B. Heczko and M. Bulanda. 2013. Molecular epidemiology, plasmid analysis, virulence, and resistance of Escherichia coli isolated from neonatal intensive care units in Poland. Diagn. Microbiol. Infect. Dis. 76: 542-545.

Chmielarczyk A., J. Wojkowska-Mach, D. Romaniszyn, P. Adamski, E. Helwich, R. Lauterbach, M. Pobiega, M. BorszewskaKornacka, E. Gulczynska, A. Kordek and others. 2014. Mode of delivery and other risk factors for Escherichia coli infections in very low birth weight infants. BMC Pediatr. 14: 274.

Clermont O., S. Bonacorsi and E. Bingen. 2000. Rapid and simple determination of the Escherichia coli phylogenetic group. Appl. Environ. Microbiol. 66: 4555-4558.

Clermont O., H. Dhanji, M. Upton, T. Gibreel, A. Fox, D. Boyd, M.R. Mulvey, P. Nordmann, E. Ruppe, J.L.Sarthou and others. 2009. Rapid detection of the O25b-ST131 clone of Escherichia coli encompassing the CTX-M-15-producing strains. J. Antimicrob. Chemother. 64: 274-277.

Cordero L., R. Rau, D. Taylor and L.W. Ayers. 2004. Enteric gram-negative bacilli bloodstream infections: 17 years' experience in a neonatal intensive care unit. Am. J. Infect. Control 32: 189-195. Cortes G., N. Borrell, B. de Astorza, C. Gomez, J. Sauleda and S. Alberti. 2002. Molecular analysis of the contribution of the capsular polysaccharide and the lipopolysaccharide $\mathrm{O}$ side chain to the virulence of Klebsiella pneumoniae in a murine model of pneumonia. Infect. Immun. 70: 2583-2590.

Damjanova I., A. Toth, J. Paszti, G. Hajbel-Vekony, M. Jakab, J. Berta, H. Milch and M. Fuzi. 2008. Expansion and countrywide dissemination of ST11, ST15 and ST147 ciprofloxacin-resistant CTX-M-15-type beta-lactamase-producing Klebsiella pneumoniae epidemic clones in Hungary in 2005--the new 'MRSAs'? J. Antimicrob. Chemother. 62: 978-985.

Denkel L.A., F. Schwab, A. Kola, R. Leistner, L. Garten, K. von Weizsäcker, C. Geffers, P. Gastmeier and B. Piening. 2014. The mother as most important risk factor for colonization of very low birth weight (VLBW) infants with extended-spectrum beta-lactamase-producing Enterobacteriaceae (ESBL-E). J. Antimicrob. Chemother. 69: 2230-2237.

Diancourt L., V. Passet, J. Verhoef, P.A. Grimont and S. Brisse. 2005. Multilocus sequence typing of Klebsiella pneumoniae nosocomial isolates. J. Clin. Microbiol. 43: 4178-4182.

Drieux L., F. Brossier, W. Sougakoff and V. Jarlier. 2008. Phenotypic detection of extended-spectrum beta-lactamase production in Enterobacteriaceae: review and bench guide. Clin. Microbiol. Infect. 14 Suppl 1: 90-103.

Fang C.T., S.Y. Lai, W.C. Yi, P.R. Hsueh, K.L. Liu and S.C. Chang. 2007. Klebsiella pneumoniae genotype K1: an emerging pathogen that causes septic ocular or central nervous system complications from pyogenic liver abscess. Clin. Infect. Dis. 45: 284-293.

Gastmeier P., C. Geffers, F. Schwab, J. Fitzner, M. Obladen and H. Ruden. 2004. Development of a surveillance system for nosocomial infections: the component for neonatal intensive care units in Germany. J. Hosp. Infect. 57: 126-131.

Geffers C., S. Baerwolff, F. Schwab and P. Gastmeier. 2008. Incidence of healthcare-associated infections in high-risk neonates: results from the German surveillance system for very-low-birthweight infants. J. Hosp. Infect. 68: 214-221.

Graham P.L., M.D. Begg, E. Larson, P. Della-Latta, A. Allen and L. Saiman. 2006. Risk factors for late onset gram-negative sepsis in low birth weight infants hospitalized in the neonatal intensive care unit. Pediatr. Infect. Dis. J. 25: 113-117.
Guzman-Cottrill J.A., K.A. Ravin, K.A. Bryant, D.M. Zerr, L. Kociolek, J.D. Siegel and Society for Healthcare Epidemiology of America. 2013. Infection prevention and control in residential facilities for pediatric patients and their families. Infect. Control Hosp. Epidemiol. 34: 1003-1041.

Johnson J.R. and A.L. Stell. 2000. Extended virulence genotypes of Escherichia coli strains from patients with urosepsis in relation to phylogeny and host compromise. J. Infect. Dis. 181: 261-272.

Jung S.W., H.J. Chae, Y.J. Park, J.K. Yu, S.Y. Kim, H.K. Lee, J.H. Lee, J.M. Kahng, S.O. Lee, M.K. Lee and others. 2013. Microbiological and clinical characteristics of bacteraemia caused by the hypermucoviscosity phenotype of Klebsiella pneumoniae in Korea. Epidemiol. Infect. 141: 334-340.

Karlowicz M.G., E.S. Buescher and A.E. Surka. 2000. Fulminant late-onset sepsis in a neonatal intensive care unit, 1988-1997, and the impact of avoiding empiric vancomycin therapy. Pediatrics 106: $1387-1390$.

Lombardi S., M. Scutell, V. Felice, E. Di Campli, M. Di Giulio and L. Cellini. 2014. Central vascular catheter infections in a Hospital of Central Italy. New Microbiol. 37: 41-50.

Lutsar I., C. Chazallon, F.I. Carducci, U. Trafojer, B. Abdelkader, V.M. de Cabre, S. Esposito, C. Giaquinto, P.T. Heath, M.L. Ilmoja and others. 2014. Current management of late onset neonatal bacterial sepsis in five European countries. Eur. J. Pediatr. 173: 997-1004. Makhoul I.R., P. Sujov, T. Smolkin, A. Lusky, B. Reichman and Israel Neonatal Network. 2005. Pathogen-specific early mortality in very low birth weight infants with late-onset sepsis: a national survey. Clin. Infect. Dis. 40: 218-224.

Mitt P., T. Metsvaht, V. Adamson, K. Telling, P. Naaber, I. Lutsar and M. Maimets. 2014. Five-year prospective surveillance of nosocomial bloodstream infections in an Estonian paediatric intensive care unit. J. Hosp. Infect. 86: 95-99.

Monstein H.J., A. Ostholm-Balkhed, M.V. Nilsson, M. Nilsson, K. Dornbusch and L.E. Nilsson. 2007. Multiplex PCR amplification assay for the detection of blaSHV, blaTEM and blaCTX-M genes in Enterobacteriaceae. APMIS 115: 1400-1408.

Nagao M. 2013. A multicentre analysis of epidemiology of the nosocomial bloodstream infections in Japanese university hospitals. Clin. Microbiol. Infect. 19: 852-858.

Oteo J., O. Cuevas, I. Lopez-Rodriguez, A. Banderas-Florido, A. Vindel, M. Perez-Vazquez, V. Bautista, M. Arroyo, J. GarciaCaballero, P. Marín-Casanova and others. 2009. Emergence of CTX-M-15-producing Klebsiella pneumoniae of multilocus sequence types $1,11,14,17,20,35$ and 36 as pathogens and colonizers in newborns and adults. J. Antimicrob. Chemother. 64: 524-528.

Ozkan H., M. Cetinkaya, N. Koksal, S. Celebi and M. Hacimustafaoglu. 2014. Culture-proven neonatal sepsis in preterm infants in a neonatal intensive care unit over a 7 year period: coagulase-negative Staphylococcus as the predominant pathogen. Pediatr. Int. 56: 60-66. Pan Y.J., T.L. Lin, Y.H. Chen, C.R. Hsu, P.F. Hsieh, M.C. Wu and J.T. Wang. 2013. Capsular types of Klebsiella pneumoniae revisited by wzc sequencing. PLoS One 8: e80670.

Rozanska A., J. Wojkowska-Mach, M. Borszewska-Kornacka, A. Cmiel, J. Gadzinowski, E. Gulczynska, E. Helwich, A. Kordek, D. Pawlik, J. Szczapa and others. 2012. Antibiotic consumption and its costs of purchase in Polish neonatology networks units. Przegl. Epidemiol. 66: 513-519.

Soto S.M., J. Bosch, M.T. Jimenez de Anta and J. Vila. 2008. Comparative study of virulence traits of Escherichia coli clinical isolates causing early and late neonatal sepsis. J. Clin. Microbiol. 4: 1123-1125. Stoll B.J., N. Hansen, A.A. Fanaroff, L.L. Wright, W.A. Carlo, R.A. Ehrenkranz, J.A. Lemons, E.F. Donovan, A.R. Stark, J.E. Tyson and others. 2002. Changes in pathogens causing earlyonset sepsis in very-1 ow-birth-weight infants. N. Engl. J. Med. 347: 240-247. 
Stoll B.J., N.I. Hansen, P.J. Sanchez, R.G. Faix, B.B. Poindexter, K.P. Van Meurs, M.J. Bizzarro, R.N. Goldberg, I.D. Frantz, E.C. Hale and others. 2011. Early onset neonatal sepsis: the burden of group B Streptococcal and E. coli disease continues. Pediatrics 127: 817-826.

Turton J.F., H. Baklan, L.K. Siu, M.E. Kaufmann and T.L. Pitt. 2008. Evaluation of a multiplex PCR for detection of serotypes K1, $\mathrm{K} 2$ and $\mathrm{K} 5$ in Klebsiella sp. and comparison of isolates within these serotypes. FEMS Microbiol. Lett. 284: 247-252.

Vergnano S., E. Menson, N. Kennea, N. Embleton, A.B. Russell, T. Watts, M.J. Robinson, A. Collinson and P.T. Heath. 2011. Neonatal infections in England: the NeonIN surveillance network. Arch. Dis. Child. Fetal Neonatal Ed. 96: F9-F14.

Vimont S., B. Mnif, C. Fevre and S. Brisse. 2008. Comparison of PFGE and multilocus sequence typing for analysis of Klebsiella pneumoniae isolates. J. Med. Microbiol. 57: 1308-1310.

Watt S., P. Lanotte, L. Mereghetti, M. Moulin-Schouleur, B. Picard and R. Quentin. 2003. Escherichia coli strains from pregnant women and neonates: intraspecies genetic distribution and prevalence of virulence factors. J. Clin. Microbiol. 41: 1929-1935.
Weston E.J., T. Pondo, M.M. Lewis, P. Martell-Cleary, C. Morin, B. Jewell, P. Daily, M. Apostol, S. Petit, M. Farley and others. 2011. The burden of invasive early-onset neonatal sepsis in the United States, 2005-2008. Pediatr. Infect. Dis. J. 3: 937-941.

Wirth T., D. Falush, R. Lan, F. Colles, P. Mensa, L.H. Wieler, H. Karch, P.R. Reeves, M.C. Maiden, H. Ochman and others. 2006. Sex and virulence in Escherichia coli: an evolutionary perspective. Mol. Microbiol. 60: 1136-1151.

Wojkowska-Mach J., A. Chmielarczyk, M. Borszewska-Kornacka, J. Domanska, J. Gadzinowski, E. Gulczynska, M. Nowiczewski, E. Helwich, A. Kordek and others. 2013. Enterobacteriaceae infections of very low birth weight infants in Polish neonatal intensive care units: resistance and cross-transmission. Pediatr. Infect. Dis. J. 32: 594-598.

Wojkowska-Mach J., E. Gulczynska, M. Nowiczewski, M. Borszewska-Kornacka, J. Domanska, T.A. Merritt, E. Helwich, A. Kordek, D. Pawlik, J. Gadzinowski and others. 2014. Late-onset bloodstream infections of Very-Low-Birth-Weight infants: data from the Polish Neonatology Surveillance Network in 2009-2011. BMC Infect. Dis. 14: 339-2334-14-339. 
